\title{
Self-Reported Learning Effects of a Tagging Activity Carried out in a Personal Learning Environment (PLE) by Secondary-School Pupils
}

\author{
Dominique Verpoorten ${ }^{1}$, Christian Glahn ${ }^{1}$, Mohamed Amine Chatti ${ }^{2}$, Wim Westera ${ }^{1}$, \\ Marcus Specht ${ }^{1}$ \\ CELSTEC, Open University of the Netherlands ${ }^{1}$, University of Aachen ${ }^{2}$
}

\begin{abstract}
This paper reports on the use of a Web 2.0 solution by sixteen 14/15 year-old pupils in a formal learning context. The gathered data provides a first appreciation of how the participants saw the action of tagging resources as affecting five dimensions of their learning experience: satisfaction, judgment of learning, effect on recall, effect on understanding and sense of personalization of the learning sequence. Based on these self-reported judgments, a discussion is opened on the mere decision to divert highly complex Web 2.0 tools into "ordinary" learning tools. The study also raises side questions about how pupils give an account of their learning experience and how they balance, or not, content and process aspects is such a description.
\end{abstract}

\section{Introduction}

Personal Learning Environments, widget technology, social software, all Web 2.0 services and social software are gaining momentum $[1,2]$ and have even been portrayed as the future of education $[3,4]$. The widget technology that is used in personal learning environments (PLEs) enables learners to structure and to aggregate information from different sources, such as Wikis, Blogs, social bookmarking, or resource sharing. The integration of personal services is considered as the future of online learning. However, the contribution of PLEs to regular school instruction has received little attention so far. This paper reports a case study about incorporating the PLE solution "Personal Learning Environment Manager" (PLEM) into lesson-centered learning activities in a Belgium School. A team at the computer sciences department of the RWTH Aachen developed PLEM [5]. While using this tool, students got acquainted with the tagging of the resources they found, that is with a common action conveyed and bolstered by the development of the Web 2.0.

\section{Formal learning support of the Web 2.0}

The initial question for this case study addressed the usefulness of applying PLEM in formal education: Does it make sense to make a limited use of so a complex Web 2.0 tool, as PLEM, in a traditional educational environment such as a classroom?

The research to date has seldom taken the use of Web 2.0 solutions in formal instruction contexts as a topic of investigation. And widgets that claim to have a link with the realm of school are far less numerous than widgets conceived for other domains. A quick search, conducted on April 5, 2010, on Yahoo Widgets website with the keywords "school", "education" and "learning" returns respectively 19, 47 and 70 results while games, calendar, finance or news return 641, 105, 93 and 812 results. Neither in Google Gadgets nor in Apple Dashboard Widgets is education listed in the categories. In addition, a closer look shows that most widgets retrieved for the three keywords (school, learning, education) are foreign to regular classroom or e-learning course, to say nothing of the sickening "Last day of school countdown" widget.

Up to now, the available scientific literature does not put a lot into this issue of infusing Web 2.0 technologies in formal education. Its efforts mainly bear on mash-up integration of existing widgets and third-party tools with institution-centric information, services, LMSs and VLEs [6, 7, 8]. Concerns about architecture, interoperability and reusability are dominant and these technical issues remain impenetrable, if not incomprehensible, for the educator who sticks to a basic concern: what it means to work with these new technological artifacts and how this affects the type of educational support offered to the students? Technological development takes for granted that existing tools and widgets can be loaded with enough instructional value to be used in relation with formal instruction processes or units of learning [9], which might turn not to be the case or only at certain conditions sometimes hard to achieve at school. 
Current research also assumes that student's personal learning environments (PLEs) composed of widgets not offered by the institution should remain available as support for regular courses [10], which also might not be the case. For instance, Hardy et al. [11] show that even when undergraduates do have a good level of IT competence and confidence, they tend to be conservative in their approaches to university study, maintaining a clear separation between technologies for learning and for social networking. Based on a correlation between a high usage of social networking sites (like Facebook) while studying and lower grades, Kirschner and Karpinski [12] suggest that blurring this separation might even be detrimental to learning. Margaryan and Littlejohn [13] lean on their findings on the low level of use of and familiarity with collaborative knowledge creation tools, virtual worlds, personal Web publishing, and other emergent social technologies, to cast doubts on the ability or the wish of students to use complex digital tools in their learning practice.

It is therefore important to keep technological development and real-world experimentation with teachers and students in parallel, otherwise there is a risk to solve highly technical challenges while basic instructional practice is neglected.

\subsection{Tagging resources}

The term tagging describes the labeling of resources by using free-form key words - the tags. The tagging of resources is widely adopted by social software services [14] and results in user-generated metadata. So-called "tag clouds" have emerged along with. A tag cloud is a visualization of tag distributions that associates frequencies of tag occurrences to font sizes or color schemes (see Figure 1). As much as a table of contents can do for a book and a menu of categories can do for a website, tag clouds provide a visual means for users to form a general impression of the underlying set of content and a "gist" of what the site is about [15].

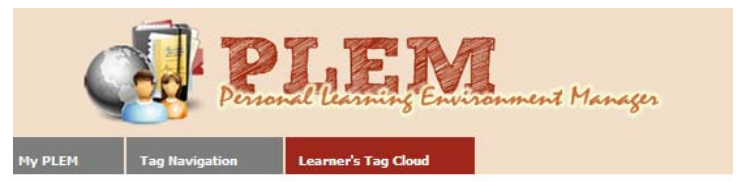

69.myid.net 's Tags

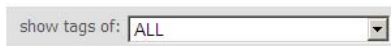

19 siede 19thcentury belge béatifié canonisé catholic christ fatherdamian flamand

lépreux missionary missionnaire molokai news prêtre pere damien
Figure 1 . The PLEM tags cloud of a participant

A number of scientific contributions have focused on tagging as a type of community driven creation of meta-data $[16,17,18]$, or have studied tags as a way to improve the accessibility of contents $[19,20]$.

Only a modicum of empirical studies specifically address the cognitive and learning effects of the action of tagging on individuals. De Smet, Van Keer, and Valcke [21] have argued that tagging of own actions with a pre-defined vocabulary supports peer tutor's meta-cognitive processes. Shergold, Davies, and Lamour [22] used a list of fixed keywords to help learners to identify own skills. Glahn, Specht, and Koper [23] studied the potential of tag clouds to support the reflection on personal learning processes and to stimulate awareness of incidental learning experiences. They point out that personal tag clouds and the use of highlighted tags can stimulate reflection on the tagging activity of learners and help them to evaluate and to monitor the semantic structure of the resources that they have found on the Web. Individual benefits of the tagging activity are also addressed by Budiu, Pirolli, \& Hong [24] who observe contrasted effects of tagging-by-typing versus tagging-by-clicking on both recognition and recall tests for the original material.

The present study differs from the previous research with respect to the following aspects: (a) it takes place in a formal learning context, (b) it is set up in a secondary-level school, (c) it gives room to perceived contribution of tagging to generic skills acquisition (recall, understanding) and not only to externally scored performance.

\section{Method}

\subsection{Context and assignment}

The study took place in a "Catholic studies" class offered to pupils aged 14 to 15 at the European School Mol (Belgium). During a lesson of 45 minutes, they were asked to search for Web resources on an assigned topic (the Belgian missionary Father Damian), to add and tag these resources in their PLEM (Personal Learning Environment Manager) and to look at the evolution of their tag cloud.

\subsection{Tooling}

PLEM is a rich tool providing facilities to qualify and orchestrate a personal collection of Web resources. It offers many functions (see Figure 2) and is underpinned by complex notions like "collective intelligence" and "long tail theory". 


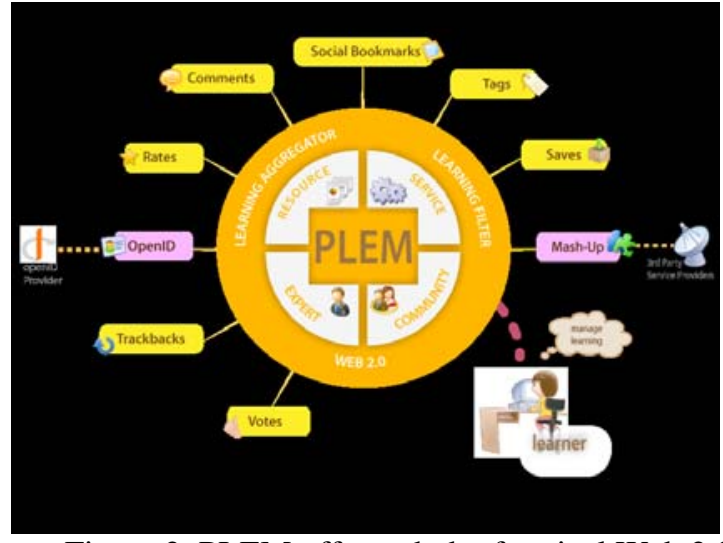

Figure 2. PLEM offers a hub of typical Web 2.0 functions

Learners can log into PLEM and create a personalized space, where they easily aggregate, manage, tag, rate, and share learning resources of interest. An example of such a space is depicted in Figure 3. As an aggregator, PLEM enables learners to pull together learning resources from more than one source, remix and assemble them to form a new and personal "learning collection". Learning collections are made available and easy to search and reuse by the PLEM community. In addition, PLEM offers a distributed voting mechanism to locate quality learning resources. Each qualifying action of a learning entity (e.g. comment, link, save, like, rate, vote, view, share) counts as one vote for that learning entity. The mean value of all votes for a given learning entity is then used to measure its popularity.

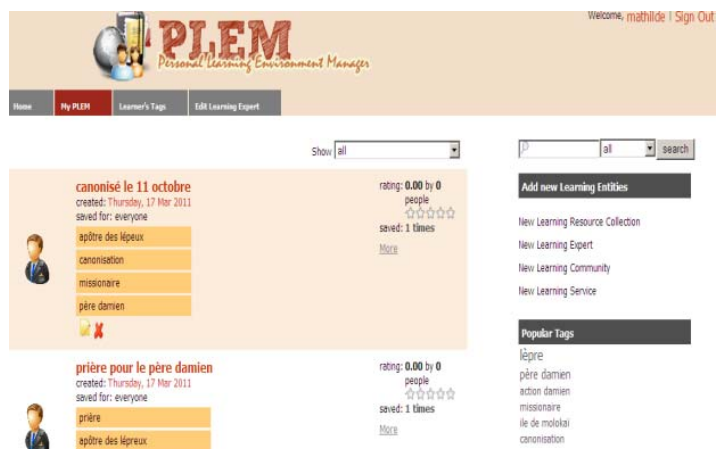

Figure 3. A participant's PLEM personal space for tagging, commenting, rating, sharing learning resources.

\subsection{Tagging for learning}

In the wealth of functions offered by PLEM, the lesson plan chosen for this study concentrates on the tagging activity. Pupils are requested to assign freechosen keywords to the Web resources they found on the topic and to observe the evolution of their personal tag cloud. (The observations and questionnaires of this study bundle the tagging activity and the tag cloud follow-up. No specific effect of one or the other action is assessed).
Most Web 2.0 concepts emphasize that resources and their qualifications can get shared among the participants in the social network of a service. In the present study mutual sharing of bookmarks and comparison with peers' tags were excluded from the learning activity. Therefore, the pupils' assignment limits the available functions of PLEM and restricts the social dimension. Based on recent studies, this focus on individual usage has a legitimacy of its own. Glahn [25] recently pinpointed that learners' main use of tagging and tag clouds was not "social" in the first place but initially guided by personal "information management" needs. In the same line of reasoning Panke \& Gaiser [26] found that retrieving and storing information via tagging seemed to meet users' need for personal management of resources much more than for information sharing.

\subsection{Procedure}

Pupils were introduced to the tool during a 20 minutes session just before the beginning of the lesson. After the lesson, pupils answered an evaluation questionnaire meant to ascertain aspects of their learning experience: overall appreciation of the instructional sequence, feeling of learning, perceived contribution of the learning activity to understanding and memorization and contribution of the PLEM-based activity to an enhanced personalization of the unit of learning.

\subsection{Data gathering}

Three methods were used to collect data.

3.5.1. Questionnaires. This type of data covers participants' answers recorded through the online service Questback. The background questionnaire only asked pupils to self-evaluate their mastery level of the lesson's topic. The evaluation questionnaire comprised 23 questions (in four sections) meant to examine:

- The pupils' appreciation of the PLEM task and its level of complexity;

- $\quad$ The pupils' judgement of learning, viz. questions asking students to report the learning they believe they achieved as a consequence of having taken the lesson [27, 28];

- The pupils' evaluation of the benefit that can be brought by the mere process of filling in a questionnaire [29] about their learning experience;

- The pupils' understanding of PLEM and its functionalities.

Self-reported evaluations therefore form the major part of the gathered data. This approach that takes "student's voice" as the main material for the investigation was adopted for the following reasons: 
- From a research perspective, it is important to achieve more objective evaluations of subjectivity [30, 31], especially regarding the acceptance and real use of new TEL (technology enhanced learning) appliances;

- From an instruction perspective, asking for students' opinion upon the learning sequence they experience might be a (meta-)learning vehicle of its own right. In their work on "reflection amplifiers", seen as structured opportunities for students to examine and evaluate various aspects of their learning experience, Verpoorten, Westera, and Specht [32] describe learners' appreciation of the task, judgment of learning and other auto-cognitive and rating instruments as techniques to train reflection and self-awareness. The evaluation questionnaire was therefore presented to students as an integral part of the lesson;

- From a teacher/course evaluation perspective, McKeachie and Kaplan [33] express the viewpoint that students' estimation of their own learning, achievement of course goals, motivation for further learning, etc. are preferable to their evaluation of teacher or learning tools characteristics.

More generally, this article is part of a larger investigation process that positively takes what students can say about their learning experience as an object of study. Triangulations with more “objective” data were nevertheless looked for.

3.5.2. Observation of the activity outputs. This second type of data comes from the analysis of participants' inputs in PLEM. By observing their tags and personal clouds, crosschecks with some subjective claims were inquired.

3.5.3. Analysis of a consequential task. As a final and integrative task, pupils were asked to produce a text about Father Damian from as many elements they learnt through the PLEM-based sequence as possible. There was a time limit of 5 minutes for this task. The outputs were analyzed.

\section{Results}

Due to the small size of the sample, results are presented as raw figures.

\subsection{Judgment of learning}

"Judgment of learning" is defined as asking learners to report the benefits they believe they reaped as a consequence of having taken a course or a lesson. To the question "What have you learnt from the lesson?" two answers (both explicitly stated by the teacher in his introduction to the PLEM task and both clearly visible in the assignment page received by all pupils) were anticipated: (a) expected answer 1 (concerned with content): "I learnt about the life of Father Damian" (the historical character to which the Web search was dedicated), (b) expected answer 2 (concerned with process): "I learnt about using a tool called PLEM and/or about tagging documents”.

Results show that an overwhelming majority of pupils restrain their judgment of learning to contentrelated aspects (expected answer $n^{\circ} 1$ ). Only 3 pupils mention, besides content aspects, that they learnt to use a new tool or that they learnt to tag websites. A crosscheck of these ratios was organized with the reasons given by pupils for their level of satisfaction (see Figure 4) about their learning experience.

1) This learning experience was a positive one for me.

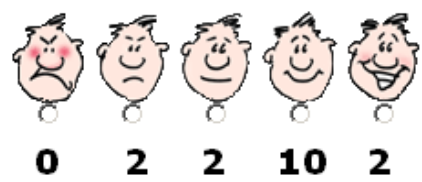

Figure 4. Two pupil claim to be very satisfied with the PLEM-based lesson, 10 satisfied, 2 indifferent, 2 not satisfied

The same low proportion of pupils aware of a procedural learning (expected answer $n^{\circ} 2$ ) is found in these reasons. The 2 unsatisfied pupils give the complexity of the tool as a justification for nonsatisfaction. The two indifferent pupils do not give consistent answers, making reference to the whole course of the teacher and not to the PLEM-based lesson. The 12 satisfied and very satisfied pupils motivate their rating by: (a) a feeling of learning about the assigned topic (5 answers), (b) the fact that such a lesson is different from regular lessons (5 answers), (c) a feeling of learning about the tool used (2 answer). Again, the portion of learning linked to procedural learning (getting acquainted with a new tool and the action of tagging) is mentioned only by 2 satisfied and very satisfied pupils, of which 1 participant was also included in the 3 "procedural pupils" on the previous question. It could be objected that the weak occurrence of the expected answer $n^{\circ} 2$ is due to a pre-existing knowledge of the tool. As they would already master this aspect of the learning experience, they would not mention it as new learning. Though no explicit question was settled thereabout, the knowledge of PLEM is quite doubtful amongst pupils, due to its still experimental dimension and to its current cryptic address. Furthermore, one question bore upon pupil's current use of Web 2.0 affordances. Only one pupil out of 16 report a prior use of social bookmarking and none of tagging. Participants appear to be mainly anchored in a "book- culture" rather than in a "Net Generation", "Homo Zappiens”, or "digital natives" as which they are sometimes portrayed. 


\subsection{Judgment on topic mastery}

Before and after their work in PLEM, pupils were asked to assess their perceived level of mastery of the assigned topic. Pupils could choose between 4 levels of knowledge going from ignorance to a detailed knowledge. According to students, the PLEM-based learning activity resulted in learning gains (Figure 5).

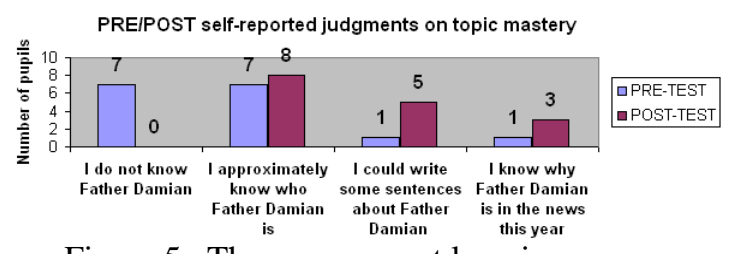

Figure 5. The group report learning progress

\subsection{Generic skills development}

Since it is doubtful that Web 2.0 technologies will convince teachers without efforts to make explicit the competence these technologies are likely to train, the study collected appreciations of how the participants saw the action of tagging as affecting their recall (see Figure 6) and understanding (see Figure 7), both considered as generic or soft skills.

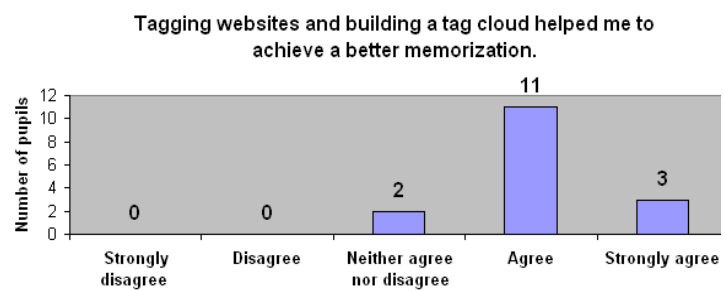

Figure 6. Pupils are affirmative about the positive impact of tagging on their memorization

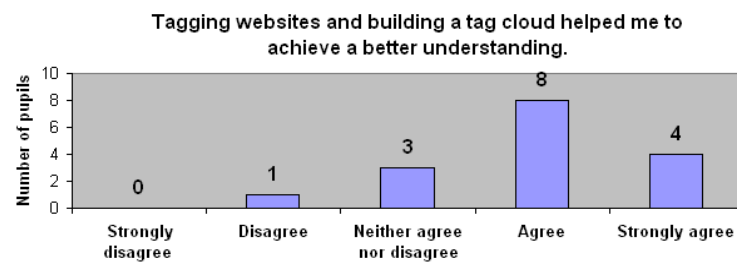

Figure 7. Pupils are affirmative about the positive impact of tagging on their understanding of the material

In an attempt to obtain objective confirmation of this positive relationship that pupils trace between tagging and recall, the final text produced by the pupils on the covered topic was analyzed. The words used in this text (column 3 in Table 1) were compared to the words used as tags (column 1 in Table 1). Words used in both were supposed to be evidence of improved memorization.
Table 1. Comparison of tags with words in the final text

\begin{tabular}{|l|l|l|l|}
\hline & $\begin{array}{l}\text { Tags on resources } \\
\text { (in brackets, } \\
\text { number of Web } \\
\text { resources) }\end{array}$ & $\begin{array}{l}\text { Tags in the } \\
\text { personal } \\
\text { cloud }\end{array}$ & $\begin{array}{l}\text { Words in } \\
\text { the final } \\
\text { text }\end{array}$ \\
\hline Pupil 1 & $34(3)$ & 25 & 7 \\
\hline Pupil 2 & $12(2)$ & 12 & 6 \\
\hline Pupil 3 & $23(4)$ & 22 & 7 \\
\hline Pupil 4 & $7(2)$ & 6 & 3 \\
\hline Pupil 5 & $5(1)$ & 5 & 6 \\
\hline Pupil 6 & $16(2)$ & 14 & 10 \\
\hline Pupil 7 & $20(3)$ & 20 & 13 \\
\hline Pupil 8 & $11(3)$ & 10 & 4 \\
\hline Pupil 9 & $6(1)$ & 6 & 5 \\
\hline Pupil 10 & $15(2)$ & 10 & 5 \\
\hline Pupil 11 & $26(4)$ & 26 & 4 \\
\hline Pupil 12 & $38(6)$ & 16 & 13 \\
\hline Pupil 13 & $13(2)$ & 10 & 4 \\
\hline Pupil 14 & $18(4)$ & 15 & 2 \\
\hline Pupil 15 & $12(4)$ & $48(9)$ & 3 \\
\hline Pupil 16 & & 7 & 7 \\
\hline
\end{tabular}

The results show large variations in the combinations of figures. Even high achievers such as pupil 12 or pupil 16 exhibit different patterns in terms of visited websites, re-use of tags and exploitation of the tags in their final text. The use of many tags does not necessarily reflect the number of resources and may not explain the concepts of the pupil's personal tags cloud. Furthermore this data raises the question why high-achiever 12 for instance seems to make an intensive use of its clouded tags in the final test, whereas high achiever 16, though many tags used during the study phase, do not relate tags to the final text, as if some filtering process had occurred during the activity In any case, conclusive results regarding influences of tagging on recall, cannot be drawn at this stage and the self-reported judgments given by pupils on this relationship cannot be confirmed by this factual data.

\subsection{Contextualization of the tagging activity}

A section of the evaluation questionnaire aimed at identifying participant perceptions on engaging with a learning event like the PLEM-based lesson. The purpose was to investigate how they hypothetically posited the exploration of the topic done with the support of PLEM against other possible modes of engagement with the topic: regular chalk-and-talk teaching, collaborative learning, drill-and-practice exercises, etc. These possibilities replace the PLEM exercise into the general issue of the diversification of learning methods [34, 35]. The PLEM assignment 
appears as one learning event among others. The questions related to this issue requested an effort of imagination. Pupils were asked to give what would be the best location of the PLEM tagging exercise in a broader sequence on the topic that would comprise a lecture on the topic. Would the pupil put the tagging exercise before or after this lecture? Answers are given in Figure 8.

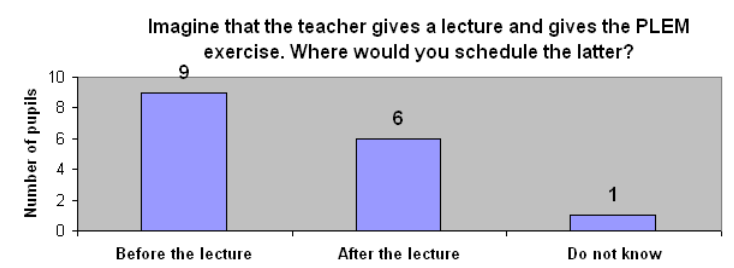

Figure 8. Ideal location of the PLEM exercise in a broader unit of learning

Interestingly, the relatively balanced pupils' opinions observed in Figure 7 regarding different possible instructional arrangements were similarly obtained in a previous research conducted in another domain (physics) with another tool: the ELEKTRA serious game [36]. On a sample of 49 pupils (see Figure 9), exactly the same number of pupils was found that would prefer having the game before and after the regular lecture.

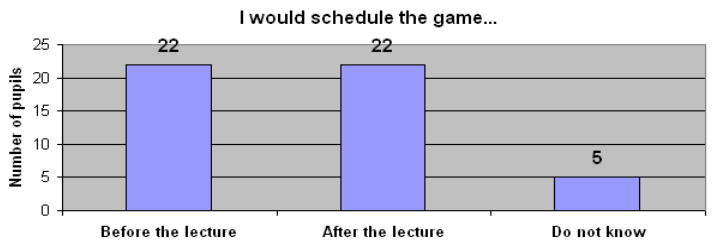

Figure 9. Ideal sequencing of a physics game in a broader unit of learning

On the whole, therefore, it seems that students have variegated opinions about possible learning sequences and about the one that would best fit to the perception they have of their own learning needs, no regard if these are correct or not.

\section{Discussion}

Three findings emerge from the present study. Two are relevant to the approach of Web 2.0 tools in secondary school settings. One is incidental and relate to the reporting by students of what they experienced when confronted to a learning task.

\subsection{Scaffolds towards Web 2.0 tools are needed}

In the area of personal learning environment research, Mödritscher et al. [37] have developed this daring pedagogical assumption: "we consider the learning environment an important part of the learning outcome as opposed to an instructional condition. Therefore, learners design their learning environment by establishing a network of people, artifacts, and tools (manually or with the support of personalization services) and interacting with that environment" (see also [38]). This stance, very interesting but demanding in regard to the development of meta-learning abilities, establishes a macro-competence ("I am capable of designing my learning environment”) but does not provide any clue about the scaffolding needed to achieve it. Obviously, the pupils having participated to the present study are far from this ambitious objective. Here, PLEM has been restricted to tagging functionalities. Despite this drastic amputation, the majority of pupils found that the task is at a right or at a high level of complexity (see Figure 9).

\section{The task's level of complexity was:}

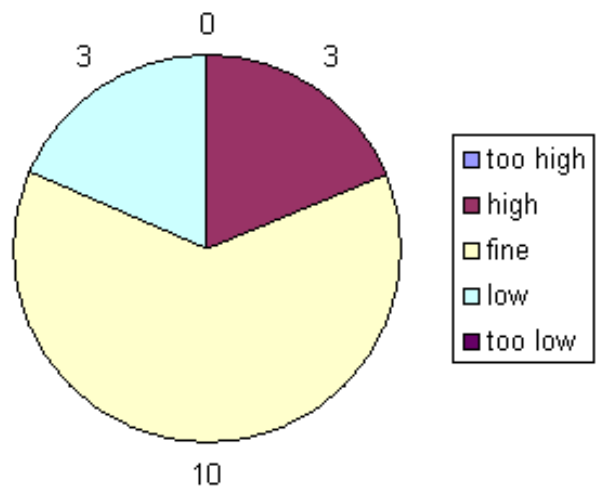

Figure 10. Even restricted and tutored use of PLEM represents a fine or high level of complexity for pupils

When asked to describe what PLEM is, only 2 pupils out of 16 managed to give an answer reflecting the specifics of the tool. How can a pupil be guided to the understanding and the optimal management of a personal learning environment? It seems that focused tasks, like the one used for this experiment, support pupils to achieve the intended learning goals by using a PLE. This structured approach seems to contradict the autonomy, freedom and personalization principles inherent to PLEs literature. Meanwhile, the findings suggest that the following aspects constraint educational use of PLEs:

- The pupils have not developed a high level of self-regulation competences;

- The pupils' understanding and utilizing of Web2.0 services cannot be taken for granted;

- The pupils need to develop the underlying knowledge and the skills to use PLEs effectively. 
Downplaying these observations can induce unawareness to the conditions of acceptance and use in real-world instruction settings.

\subsection{Account of the learning experience}

One observation of this study goes beyond the use of PLEM. It touches upon the ability of pupils to describe their experience of learning during a lesson. In all humanities courses, it is admitted that students must be able to provide clear, structured, detailed answers to questions about any covered topic. The topic "learning" - the basic activity of a student might be an exception. The participants to this study have 9 to 10 years tuition behind them and they do not seem to be well trained to produce an integrated account of a learning experience. Researchers (Schön, Bateson, and Kolb) highlighted for many years the importance of notions like meta-cognition, meta-learning, and learning to learn for supporting learning. Educational practice is supposed to gradually develop the learners' awareness of what helps or hampers a consistent orchestration of the various dimensions of their learning processes. In contrast with these strong and recurrent calls, the procedural aspects (the "how I learnt") are missing in the description of the PLEM-based activity produced by the pupils. This finding invites to further elaborate the notion of "instructional meta-cognitive knowledge” as introduced by Elen and Lowyck [39]. The term is defined as awareness and knowledge about the learning potential of (elements of) instructional environments. Instructional metacognitive knowledge may constitute an important mediating variable that accounts for the lack of direct effects of instructional media, methods or interventions on learning outcomes.

\section{Conclusion}

Merrill, Drake, Lacey, and Pratt [40] stated a major difference between formal and informal learning: "Students are persons who submit themselves to the acquisition of specific knowledge and skill from instruction, learners are persons who derive meaning and change their behavior based on their experiences. All of us are learners, but only those who submit themselves to deliberate instructional situations are students". This article reported on a case study to apply a Web 2.0 tool in a formal education context.

A small-scale questionnaire survey explored the perspectives of secondary level pupils' on their first encounter with PLEs through the PLEM tool. Satisfaction, feeling of learning, perceived effects of the tool on generic competence have been documented. The results suggest the need for more investigation of real-world practice and of scaffolding techniques towards an autonomous usage of Web 2.0 solutions in formal education.

The study also identified research challenges related to the development of instructional metacognitive knowledge. These challenges are concerned with students' ability to realize and express how they are piloting a learning activity which necessarily requires attention to and interactions of content, processes, tools and goals. This study shows that part of these elements are frequently absent from students' accounts of their learning experience (section 3.1). More precise questions (sections 3.3 and 3.4) on the learning experience notwithstanding indicate that students are able to reflect about the learning task (instruction) and about their personal position within it (relationship to "my" learning). From there, it is suggested that a systematic investigation of how students report on the learning context they are committed to might shed light on learning success and tribulation.

\section{Acknowledgement}

The authors are grateful to the pupils and the teacher, Mr. Villars, who welcomed them in their classroom.

\section{References}

[1] C. Owen, "Market Map: Gadget et Widget Universe“, 2007. Retrieved 4 April, 2011, from

http://www.firstpartner.net/upload/pdf1231772560746.pdf

[2] S. Wilson, "Patterns of personal learning environments“, 2008. Retrieved 4 April, 2011, from http://digitalcommons.bolton.ac.uk/iec_journalspr/4

[3] G. Attwell, "Personal Learning Environments - the future of eLearning?", 2007. Retrieved 4 April, 2011, from http://www.elearningeuropa.info/files/media/media11561.pdf

[4] D. Jones, "PLES: framing one future for lifelong learning, e-learning and universities“. Paper presented at the 5th International Lifelong Learning (Ascilite), Melbourne, 2008.

[5] M. Chatti, Anggraeni, M. Jarke, M. Specht, and K. Maillet, K. "PLEM: a Web 2.0 driven Long Tail aggregator and filter for e-learning“, International Journal of Web Information Systems, 6(1), 2010, pp. 5-23.

[6] J.I. Asensio-Perez, M.L. Bote-Lorenzo, G. VegaGorgojo, Y.A. Dimitriadis, E. Gomez-Sanchez, E., and E.D. Villasclaras-Fernandez, "Adding mash-up based tailorability to VLEs for scripted Collaborative Learning“, 2008. Paper presented at the 1st Workshop MUPPLE'08, Maastricht, The Netherlands, 2008. Retrieved 4 April, 2011, from http://titan.feyts.uva.es/uploaded_files/62412_asensioperez.pdf 
[7] O. Casquero, J. Portillo, R. Ovelar, J. Romo, and M. Benito, M., "iGoogle and gadgets as a platform for integrating institutional and external services". Paper presented at the 1st Workshop MUPPLE’08, Maastricht, The Netherlands, 2008. Retrieved 4 April, 2011, from http://ftp.informatik.rwth-aachen.de/Publications/CEURWS/Vol-388/casquero.pdf

[8] S. Wilson, P. Sharples, P., and D. Griffiths, "Distributing education services to personal and institutional systems using Widgets". Paper presented at the 1st Workshop MUPPLE'08, Maastricht, The Netherlands, 2008. Retrieved 4 April, 2011, from http://dspace.learningnetworks.org/handle/1820/1558

[9] L. de la Fuente Valentín, D. Leony, A. Pardo, and C. Delgado Kloos, "Mashups in Learning Design: pushing the flexibility envelope". Paper presented at the 1st Workshop MUPPLE'08, Maastricht, The Netherlands, 2008. Retrieved 4 April, 2011, from http://ftp.informatik.rwth-aachen.de/Publications/CEURWS/Vol-388/valentin.pdf

[10] S. Verjans, H. Hermans, M. Bertrand, J. Eshuis, D. Janssen and F. Mofers, "Principes voor een Persoonlijke Leer- en Werkomgeving voor de Open Universiteit Nederland" [Principles for a personal learning and work environment for the Open University in the Netherlands], Instellingsbreed Programma Onderwijs (IPO), Heerlen, The Netherlands, 2008. Retrieved 4 April, 2011, from http://dspace.ou.nl/handle/1820/1921

[11] J. Hardy, D. Haywood, S. Bates, J. Paterson, S. Rhind, H. Macleod, and J. Haywood, "Expectations and Reality: Exploring the use of learning technologies across the disciplines". Paper presented at the Sixth International Conference on Networked Learning, Halkidiki, Greece, 2008. Retrieved 4 April, 2011, from http://homepages.ed.ac.uk/jhaywood/papers/Hardy_et_al.p $\mathrm{df}$

[12] P. A. Kirschner, and A.C. Karpinski, A. C., "Facebook and academic performance", Computers in Human Behavior, 26(6), 2010, pp. 1237-1245.

[13] Margaryan, A., \& Littlejohn, A., "Are digital natives a myth or reality? Students' use of technologies for learning“, 2008. Retrieved 4 April, 2011, from http://citeseerx.ist.psu.edu/viewdoc/summary?doi=10.1.1.1 72.7940

[14] G. Smith, Tagging, people-powered metadata for the social web, Berkley, CA: Prentice Hall, 2008.

[15] A.W. Rivadeneira, D.M. Gruen, M.J. Muller, and D.R. Millen, D.R., "Getting our heads in the clouds: toward evaluation studies of tag clouds". Paper presented at the Conference on Human Factors in Computing Systems, 2007, pp. 995-998.

[16] P. Heymann, P., and H. Garcia-Molina, "Collaborative creation of communal hierarchical taxonomies in social tagging systems“, InfoLab Technical Report, Computer Science Department, Stanford University, 2007.
[17] W.T. Hsieh, W.S. Lai, W.S., and S.C.T. Chou S.C.T., "A collaborative tagging system for learning resources sharing“. In A. Méndez-Vilas, A. Solano Martín, J.A. Mesa González, \& J. Mesa González (Eds.), Current developments in technology-assisted education, vol. II: technological science education, collaborative learning, knowledge management, pp. 1364-1368, Badajoz, Spain: Formatex, 2006.

[18] J. Yew, F. P. Gibson, and S. D. Teasley, "Learning by Tagging: The Role of Social Tagging in Group Knowledge Formation“, MERLOT Journal of Online Learning and Teaching, 2(4), 2006, pp. 275-285.

[19] T. Ishikawa, P. Klaisubun, P., and M. Honma, M, "Navigation Efficiency of Social Bookmarking Service". Proceedings of the International Conference on WebIntelligence and Intelligent Agent Technology Workshops, WI-IATW2007, 2007, pp. 280-283.

[20] E. Michlmayr, and S. Cayzer, "Learning user profiles from tagging data and leveraging them for personal(ized) information access". Proceedings of the Tagging and Metadata for Social Information Organization Workshop, 2007. Retrieved 4 April, from http://publik.tuwien.ac.at/files/pub-inf_4595.pdf

[21] M. De Smet, H. Van Keer, and M. Valcke, M., Crossage peer tutors in asynchronous discussion groups: studying the impact of tutors labeling their interventions, Journal of Computer Assisted Learning, 24, 2008.

[22] C. Shergold, J. Davies, J., and S. Lamour, S, "Now we're talking: how tag clouds can improve skill conversations at university“. Paper presented at the 7th elearning@greenwich conference - Making it personal, Greenwich, 2009. Retrieved 4 April, from http://www.sussex.ac.uk/tldu/studentskills/skillclouds

[23] C. Glahn, M. Specht, and R. Koper, "Reflecting on web-readings with tag clouds". Paper presented at the 11th International Conference on Interactive Computer aided Learning (ICL), Valencia, 2008. Retrieved 4 April, from http://dspace.ou.nl/handle/1820/1581

[24] R. Budiu, P. Pirolli, and L. Hong, "Remembrance of things tagged: how tagging effort affects tag production and human memory". Paper presented at the 27th international conference on Human factors in computing systems, Boston, 2009. Retrieved 4 April, from http://web.mac.com/peter.pirolli/Professional/About_Me_f iles/1119-pirolli.pdf

[25] C. Glahn, "Contextual support of social engagement and reflection on the Web". Doctoral thesis. September, 18, 2009, Heerlen, The Netherlands: Open University of the Netherlands, CELSTEC. Retrieved 4 April, from http://dspace.learningnetworks.org/handle/1820/2062

[26] S. Panke, and B. Gaiser, "With My Head Up in the Clouds": Using Social Tagging to Organize Knowledge“, Journal of Business and Technical Communication, 23, 2009, pp. 318-349. 
[27] R. Azevedo, “Computer Environments as Metacognitive Tools for Enhancing Learning“, Educational Psychologist, 40, 2005, pp. 193-197.

[28] V. Richmond, P. McCroskey, P. Kearney, and T.G. Plax, "Power in the classroom VII: Linking behavior alteration techniques to cognitive learning“, Communication Education, 36, 1987, pp. 1-12.

[29] C. Ellett, K. Loup, R. Culross, J. McMullen, and J. Rugutt, "Assessing Enhancement of Learning, Personal Learning Environment, and Student Efficacy: Alternatives to Traditional Faculty Evaluation in Higher Education“, Journal of Personnel Evaluation in Education, 11(2), 1997, pp. 167-192.

[30] B. De Finetti, "Methods for discriminating levels of partial knowledge concerning a test item“, British Journal of Mathematical and Statistical Psychology, 18, 1965, pp. 87-123.

[31] D. Leclercq, “Qualités édumériques de systèmes d'évaluation pédagogique des performances cognitives des étudiants" [Assessing the qualities of assessment systems for students cognitive performance], Labset, University of Liège, Belgium, 2004.

[32] D. Verpoorten, W. Westera, and M. Specht, “A classification framework of techniques for amplifying student's reflection in e-learning courses“, Journal of Interactive Learning Research, 21(4), 2010.

[33] W.J. McKeachie, and M. Kaplan, "Persistent problems in evaluating college teaching, American Association of Higher Education Bulletin, 48(6), 1996, pp. 5-9.

[34] D. Verpoorten, C. Delfosse, and S. Jacobs, S., "Representing learning trails with the 8 Learning Events Model“. $\quad$ Retrieved 4 April, 2011, from http://www.labset.net/projets/iclass/debate1.htm

[35] D. Verpoorten, M. Poumay, and D. Leclercq, "The eight learning events model: A pedagogic conceptual tool supporting diversification of learning methods", Interactive Learning Environments, 15(2), 2007, pp. 151160.

[36] J-L. Castaigne, and D. Verpoorten, "Final ELEKTRA report: Macroadaptivity - Why a varied learning diet?", University of Liège, Belgium, 2008.

[37] M. Mödritscher, F. Wild, and S. Sigurdarson, "Language Design for a Personal Learning Environment Design Language“. Paper presented at the 1st Workshop MUPPLE'08, Maastricht, The Netherlands, 2008. Retrieved 4 April, 2011, from http://oro.open.ac.uk/25241/

[38] M. Moedritscher, and F. Wild, F., "Why not Empowering Knowledge Workers and Lifelong Learners to Develop their own Environments?". Paper presented at the I-Know 09, Graz, Austria, 2009. Retrieved 4 April, 2011, from http://oro.open.ac.uk/24978/.
[39] J. Elen, J., and J. Lowyck, “Students' views on the efficiency of instruction: An exploratory survey of the instructional metacognitive knowledge of university freshmen“, Higher Education, 36(2), 1998, pp. 231-252.

[40] M. Merrill, L. Drake, M. Lacey, M., and J. Pratt, "Reclaiming instructional design", Educational Technology, 36(5), 1996, pp. 5-7. 